C2016, Elsevier. Licensed under the Creative Commons Attribution-NonCommercialNoDerivatives 4.0 International http://creativecommons.org/about/downloads

(c) (i) (9) 


\title{
Corporate financing decisions under ambiguity: pecking order and liquidity policy implications
}

\begin{abstract}
This paper addresses the following unresolved questions from the perspective of ambiguity theory: Why do some firms issue equity instead of debt? Why did most firms retain their cash holdings instead of distributing them as dividends in recent times? How do firms change their financing policies during a period of severe financial constraints and ambiguity, or when facing the threat of an unpredictable financial crisis? We analyze how the values of the firm's equity and debt are affected by ambiguity. We also show that cash holdings are retained longer if the investors' ambiguity aversion bias is sufficiently large, while cash holdings become less attractive when the combined impact of ambiguity and ambiguity aversion is relatively low.
\end{abstract}

Keywords: Business decision-making; Ambiguity aversion; Corporate liquidity; Pecking order; Cash holdings; Dividend policy.

\section{INTRODUCTION}

Over the last three decades, there have been many developments in decision theory that improved our understanding of uncertainty. In line with Knight (1921), uncertainty can be divided into two well-defined distinct parts, risk and ambiguity. "Risk" is used to refer to any sort of uncertainty that can be defined through the existence of a probabilistic model based on one single probability assessment, which is known to the decision maker (DM). "Ambiguity" is used to refer to situations in which the DM appears to be not fully confident that his/her beliefs apply. Practically, risk is mostly used when uncertainty is calculable, i.e. both outcomes and a subjective probability distribution over outcomes can be specified. Ambiguity applies to situations where uncertainty is incalculable, i.e. where there is no clear perception of the possible outcomes or of an estimate of a single plausible probability distribution. At least since Ellsberg (1961), experimental studies in ambiguous settings have repeatedly shown that DMs usually prefer to deal with known, rather than unknown 
probabilities, thereby revealing a form of ambiguity aversion (see, f.e, Mousavi and Gigerenzer, 2014 for a discussion of risk and uncertainty).

Although the recent literature on ambiguity has provided a unified and elegant framework to address (and often solve) some financial puzzles (e.g. the equity premium puzzle and the interest rate puzzle, see Epstein and Schneider, 2010), there are still ill-understood phenomena in corporate finance, whose explanation, in our view, might benefit from the ambiguity theory perspective.

Recent studies document a secular increase in the cash holdings of some firms (Bates, Kahle and Stulz, 2009; Denis and Sibikov, 2010; Faulkender and Wang, 2006; Holberg, Phillips and Prabhala, 2014). In 2010 the Federal Reserve reported that cash holdings of U.S. corporations experienced the largest-ever increase in records going back to 1952. Cash increased very fast after 2008, growing at an annual rate of 11 percent until 2014. US non-financial companies held $\$ 1.82$ trillion of cash at the end of 2014, including technology, pharmaceutical and industrial giants, such as Apple Inc., Pfizer Inc., and General Motors Co. "The rising corporate cash balances could represent a longer-term behavioral shift in the wake of the deepest financial crisis in decades" (The Wall Street Journal, June 10, 2010). One reason could be that firms facing deep uncertainty about future transactions and vague economic perspectives may find it beneficial to pile up significant amounts of cash as a cushion. And yet, both anecdotal ${ }^{1}$ and large sample evidence points to an incentive for managers to avoid visible accumulation of cash holdings. Moreover, one would expect that the precautionary demand for cash should decrease when firms can hedge more effectively as more types of derivatives are available, e.g. as a consequence of improvements in information and financial technology since the early 1980s. Thus, the observed increase in cash holdings represents an anomaly that challenges existing theories.

Various empirical studies are inconclusive about the hierarchy or "pecking order" among different sources of funds (see Leary and Roberts, 2010, and references there). Some have documented a significant heterogeneity in corporate decisions attributed to a divergence in beliefs about the firm's value between managers and the market (see also Lins, Servaes and Tufano, 2010, about investor preferences and cross-country differences in corporate financial decisions). Behavioral explanations of corporate decisions have recently come to consider "managers'

\footnotetext{
${ }^{1}$ An often cited anecdotal example is Kirk Kerkorian's attack on Chrysler in the past century, showing that large cash holdings drew the action of shareholders who could threaten managers' position.
} 
personality traits" (Hackbarth, 2008, 2009), which may include their attitude towards ambiguity. But whether the choice between equity or debt finance is affected by managers' personality traits and their perception biases is still controversial (see, for example, Breuer, Rieger and Soypak, 2014b). Some evidence indicates that executives often believe that their common equity is undervalued by the market, but in other cases, and especially following bad periods in the stock market, CFOs tend to focus on downside risk in their analysis and think their stock is overvalued (see, f.e., Ben-David, Graham and Harvey, 2013), leading to the insight that these contrasting findings could be "reconciled by means of a behavioural perspective to corporate finance" (Hackbarth, 2008).

Our main objective is to advance a behavioural perspective for studying equity holders and debt holders decisions. We integrate ambiguity into a contingent claim model to analyse what happens when DMs are rational in all respects, except for how they perceive the firm's future. The behavioural biases impact on firm's financing decisions and, in particular, on the values of corporate securities. Our paper sets out to answer the following unresolved questions: Why do certain firms issue equity instead of debt? Why did most firms retain their cash holdings instead of distributing them as dividends in recent times? How do firms change their financing policies during a period of severe financial constraints and ambiguity, or when facing the threat of a financial crisis in the foreseeable future? Our paper tries to provide answers within the framework of a dynamic model which incorporates ambiguity and the investor's attitude towards it. Our goal is not to challenge existing works addressing such issues; rather we try to reveal some missing ingredients of corporate policies. We model the corporate decisions as real options and apply the mathematics of mixed singular control/optimal stopping methods in stochastic settings under ambiguity. In particular, we analyze how the values of the firm's equity and debt are affected by ambiguity (Propositions 1 and 2) and relate our results to the pecking order puzzle (Proposition 3); moreover, we show how ambiguity affects cash holdings and optimal dividend policies (Propositions 4 and 5). We find that the presence of a standard pecking order or its reverse may depend on the relative ambiguity aversion biases of the managers and the investors: if managers have a stronger ambiguity aversion bias than the market, then a reversal of the standard pecking order preferences can be obtained. Finally, we find that cash holdings are retained longer if the impact of the ambiguity aversion bias is sufficiently large, which is consistent with the observed change in cash holdings in periods of turbulence and vague uncertainty. 
Cash holdings become less attractive with relatively small ambiguity aversion biases, in which case the DM prefers to receive dividends instead.

\section{LITERATURE AND THEORY}

\subsection{BEHAVIOURAL CORPORATE FINANCE AND AMBIGUITY THEORY}

Corporate finance theory has recently started considering common personality traits of managers, behavioural biases, investors' sentiment in modeling the complex decision-making processes in corporations. For example, excessive optimism and overconfidence have been described as frequently observed managers' behaviours, since the survey evidence by Graham and Harvey (2001). DMs who tend to be overconfident about their abilities overestimate those abilities. Those who are overconfident about their knowledge (i.e., overconfidence in the sense of "miscalibration", see Hackbarth, 2009) tend to establish excessively narrow confidence intervals. Alternative examples of biases are due to "mental accounting" (Thaler, 1980), where DMs set reference points for the accounts that determine gains and losses (leading eventually to "disposition effects", Shefrin and Statman, 1985), and often assign different weights to events with negative or positive realizations. Thus, there may be "mistakes" that managers make because of cognitive imperfections and emotional influences, which add up to other behavioural errors by investors, too. As a result, "judgements may be based on feelings rather than underlying fundamentals" (Shefrin, 2009). These errors can create a wedge between fundamental values and market prices and may determine important implications for the practice of corporate finance.

Such distortions seem to be further amplified when financial markets are abnormally uncertain. In times of economic turbulence, like the recent recession and the financial catastrophe that erupted in August 2007, new forms of uncertainty become truly relevant in financial strategies. In particular, ignorance and ambiguity attitudes may influence the valuation processes by the managers and the 
investors $^{2}$. In an ambiguity world, people are very insecure about what they know. Consequently, small slivers of information can cause prices to leap and plummet, with decisions far from a standard probabilistic rule. In some cases, unrealistic pessimism characterizes the DM's behaviour, involving overestimating the probabilities of unfavorable events and underestimating the probabilities of favourable events. Charness and Gneezy (2010) demonstrated experimentally that people are willing to pay a price to avoid ambiguity, and this affects their financial decisions. As recent psychometric tests and experimental evidence confirm, "there is a clear evidence that an average ambiguity aversion is the typical qualitative finding" (Trautman and Van De Kuile, 2013). A recurrent issue concerns the omission of incalculable risk and the impact of investors' sentiment and ambiguity on managers' “cognitive assessment” (Kahneman and Tversky, 1979) of option values and investment/financing opportunities. Under uncertainty, DMs are not sure about the likelihood of the states of nature and their valuation of option payoffs "are subject to vagueness, behavioural biases and partial ignorance" (Driouchi, Trigeorgis and Gao, 2015).

Some papers have recently embedded ambiguity and ambiguity attitudes into economic decisions that can be described as an option exercise or optimal stopping problems. Miao and Wang (2011) employ the recursive multiple-priors utility model developed by Epstein and Wang (1994) to incorporate ambiguity in the study of real investment and exit problems. They show that ambiguity may accelerate or delay option exercise, depending on the relative degrees of ambiguity about continuation and termination payoffs. Nishimura and Ozaki (2007) apply the continuous time multiple-priors utility model developed by Chen and Epstein (2002) and show that irreversible investment decisions are delayed because of ambiguity. Asano and Shibata (2014) employ the multiple-priors utility model in the context of natural capital investment and environmental policies, while Gao and Driouchi (2013) apply this methodology to rail transit investment. These contributions employ multiple-priors models involving real options, but do not deal with corporate finance problems. In all these real option

\footnotetext{
${ }^{2}$ Various papers linked ambiguity and financial crises (see, f.e., Routledge and Zin, 2009, Boyarchenko, 2010 and Driouchi, Trigeorgis, and So, 2015).
} 
valuation models, ambiguity deforms the objective probability distribution by changing the drift of the relevant stochastic processes, leaving however the standard deviation constant.

In our paper ambiguity is taken into account following a different approach. Our ambiguity-based analysis goes beyond the maximin or "worst case" criterion of the multi-prior utility model and uses “capacities" (Gilboa, Postlewaite and Schmeidler, 2008), representing DMs beliefs in the stochastic processes of the underlying assets. The approach of dynamically consistent Choquet random walks (Kast and Lapied 2010, Kast, Lapied and Roubaud, 2014) we follow is especially suitable to model the problems in corporate finance. On one hand, it allows to model the embedded ambiguity in a simple and parsimonious way, by representing the level of ignorance, hence the attitude towards ambiguity, throughout a single parameter, $c$. More importantly, in contrast with previous frameworks, ambiguity is perceived both in the deformation of the mean and of the variance of the relevant stochastic processes, and both are a concern in corporate decision making. As a consequence, the resulting 'deformed' Brownian motion exhibiting both a lower drift and volatility than in the classical 'probabilistic' case, makes the applications to corporate finance more realistic and, at the same time, less trivial to obtain than under the alternative modeling of ambiguity. In the next section we present our model set-up.

\subsection{THE MODEL SET-UP IN THE CHOQUET FRAMEWORK}

When considering a DM facing ambiguity, the Choquet Expected Utility approach represents his/her beliefs by a non-additive unit measure, which is referred to as a capacity. Applying the Choquet integral of a capacity to a given vector of outcomes (an 'act') generates an implied probability distribution over the outcomes, on the basis of which the expected utility value is calculated. But in contrast to subjective expected utility theory, there may no longer exist a single implied probability distribution over the states of nature that applies for all acts. Rather, the implied probability distribution may change according to the ranking of the states of nature regarding the desirability of 
the outcomes obtained for them. For acts that generate the same ranking of the states of nature, i.e. comonotonic acts, the same implied probability distribution applies. So if attention is restricted to a set of co-monotonic acts only, the results are indistinguishable from subjective expected utility, with the subjective probability distribution equalling the implied probability distribution (see a.o. Schmeidler, 1989). In the Choquet Expected Utility model a capacity simultaneously represents the ambiguity experienced by the decision maker and his/her attitude towards this ambiguity ${ }^{3}$. We refer to the combined effect of the perceived ambiguity and the DM's ambiguity aversion as his/her ambiguity aversion bias.

In what follows we adopt a dynamic framework, following Kast and Lapied (2010). Suppose that the firm's asset value, $V_{t}$, follows a Choquet-Brownian process ${ }^{4}$. It is defined on the basis of a binomial lattice, where for each $s_{t}$ at time $t$, such that $0 \leq t \leq T, s_{t+1}{ }^{u}$ and $s_{t+1}^{d}$ denote the possible successors at time $t+1$ for an "up" and a "down" movement, respectively. If "up" and "down" movements have the same capacity, then $v\left(s_{t}{ }^{u} \mid s_{t}\right)=v\left(s_{t}{ }^{d} \mid s_{t}\right)=c$, where $c, 0<c<1$, is a constant that represents the DM's ambiguity about the likelihood of the states to come. If the DM is ambiguity averse, the capacity is sub-linear, so that $c<1 / 2$ (Gilboa, Postlewaite and Schmeidler, 2008). If the perceived ambiguity increases, the value of the parameter $c$ moves further away from the anchor $1 / 2$. Thus, the capacity becomes more convex (for an ambiguity averse DM) or more concave (for an ambiguity loving DM). The symmetric discrete process outlined above can be shown to converge to a continuous time generalized Wiener process with mean $m=2 c-1$ and variance $s^{2}=4 c(1-c)$. The absence of an ambiguity bias is obtained as a special case for $c=1 / 2$. Thus, the firm's asset value is given by $^{5}$ :

\footnotetext{
${ }^{3}$ Recent research differentiates between ambiguity and ambiguity attitude, but in many cases, the resulting complications tend to be circumvented by assuming (full) ambiguity aversion. Under this additional assumption the capacity only describes the ambiguity experienced by the DM (see e.g. Chateauneuf, Eichberger and Grant, 2007).

${ }^{4}$ A Choquet-Brownian process is a distorted Brownian process, where the distortion derives from the nature and intensity of preferences toward ambiguity (Kast, Lapied and Roubaud, 2014). See also Driouchi, Trigeorgis and Gao (2015). For ambiguous random walks represented by a binomial tree, Kast and Lapied (2010) assume independence of the conditional capacities and show that additive random walks converge to Brownian motions for which an increase in ambiguity decreases both the drift and the variance.

${ }^{5}$ Expression (1) is obtained from $d V_{t} / V_{t}=(r-q) d t+\sigma d W_{t}$, where $W_{t}=m t+s B_{t}$ and $B_{t}$ is a Wiener process.
} 


$$
d V_{t} / V_{t}=((r-q)+m \sigma) d t+s \sigma d B_{t}
$$

where $r$ is the discount rate, reflecting the DM's subjective valuation which is used for discounting, $q$ is the instantaneous payout, or rate of return on the firm's assets, determining the internal liquidity of the firm from its cash flows, $\sigma$ is the volatility, and $B_{t}$ is a Wiener process. For fully ambiguity averse DMs we have $-1<m<0$ and $0<s<1$, so $r-q+m \sigma<r-q$ and $0<s \sigma<\sigma$. Both drift and volatility are reduced in comparison to the case where ambiguity is absent. That is, for $c<1 / 2$ mass is shifted to the "worst state" outcome, by applying the Choquet integral ${ }^{6}$, so that the drift falls. Notice also the new result on the perceived variance of the process, which is reduced by the ambiguity aversion bias. Ambiguity aversion is an aversion to not precisely known probability distributions, which leads to "miscalibration", in the sense of a narrower confidence interval for the variance around the lower mean, resulting in an underestimation of the volatility of the associated random events.

We assume that the firm issues perpetual debt which pays a continuous coupon at the rate $C$. The firm uses its revenue to make the coupon payment or to pay equity holders' dividends. When revenues are not sufficient and in the absence of cash balances, the firm can decide either to issue new equity or to declare bankruptcy. Thus, if the revenue rate exceeds the coupon rate $(q V \geq C)$, equity holders receive dividends; if the revenue rate falls below the coupon rate, the firm dilutes equity. Equity dilution is costly and we assume that the cost of equity dilution is proportional to the proceeds from issuance. Thus, following the argument about equity dilution in Asvanunt, Broadie and Sundaresan (2011), it is equivalent to a negative dividend of $\beta(q V-C)$. Below a critical value $V_{B}$ the firm will declare

\footnotetext{
${ }^{6}$ Following Kelsey and Spanjers (2004), let the ambiguity level of a capacity $v$ at an event $E \subseteq S$ be $\Psi_{v}(\mathrm{E})=1-v(S-E)-v(E)$. For convex capacities, ambiguity levels attain non-negative values only. For example, if we let $u_{1}$ for states in $E$ and $u_{2}$ for states in $S-E$, then for $u_{1}>u_{2}$ the Choquet integral of $u$ with respect to $v$ equals $u_{1} v(E)+u_{2}(1-v(E))=u_{1} v(E)+u_{2} v(S-E)+u_{2} \Psi_{v}(\mathrm{E})$, while for $u_{1}<u_{2}$ we obtain $u_{1} v(E)+u_{2} v(S-E)+$ $u_{1} \Psi_{v}(\mathrm{E})$, that is, in each case, the bad outcome is over-weighted by the ambiguity level $\Psi_{v}$. If a DM's beliefs are represented by a convex capacity, then he puts more weight on bad outcomes than an expected utility maximize would.
} 
bankruptcy: that is, $V_{B}$ denotes the firm's endogenous default threshold and is obtained as a result of equity holders' optimization, as in Leland (1994). In the event of default, debt holders receive (1$\alpha) V_{B}$ where $\alpha$ denotes the fraction of cash flows lost due to default costs. In the next section we compute the total values of the firm's equity and debt in the presence of ambiguity, for the current value of its asset.

\subsection{EQUITY AND DEBT UNDER AMBIGUITY AVERSION}

For a given value of the firm's assets $V$, we denote the total value of its equity by $E(V)$ and the total value of its debt by $D(V)$. Using standard dynamic programming methods (see Dixit and Pindyck, 1994), in the Appendix we derive the following expression for the value of the firm's equity:

$$
E(V)=\left\{\begin{array}{ccc}
\beta\left(\rho V-\frac{C}{r}\right)+A_{2} V^{-\omega_{2}}+A_{3} V^{-\omega_{1}} & \text { if } & V_{B} \leq V<\frac{C}{q} \\
\left(\rho V-\frac{C}{r}\right)+\hat{A}_{3} V^{-\omega_{1}} & \text { if } & V \geq \frac{C}{q}
\end{array}\right.
$$

where:

$$
\begin{aligned}
& A_{2}=(\beta-1)\left(\frac{C}{q}\right)^{\omega_{2}}\left(\frac{\omega_{1}}{\omega_{1}-\omega_{2}}\right)\left[\frac{C}{r}-\left(\frac{1+\omega_{1}}{\omega_{1}}\right) \frac{C}{q-m \sigma}\right] \\
& A_{3}=-\beta\left(\rho V_{B}^{\omega_{1}+1}-\frac{C}{r} V_{B}^{\omega_{1}}\right)-A_{2} V_{B}^{\omega_{1}-\omega_{2}} \\
& \hat{A}_{3}=A_{2} \frac{\omega_{2}}{\omega_{1}}\left(\frac{C}{q}\right)^{\omega_{1}-\omega_{2}}+A_{3}-(\beta-1)\left(\frac{C}{q}\right)^{\omega_{1}} \frac{C}{(q-m \sigma) \omega_{1}}, \\
& \text { with } \rho=\frac{q}{q-m \sigma} \text { and } \omega_{1,2}=\frac{(r-q+m \sigma)-\frac{s^{2} \sigma^{2}}{2} \pm \sqrt{\left[\frac{s^{2} \sigma^{2}}{2}-(r-q+m \sigma)\right]^{2}+2 s^{2} \sigma^{2} r}}{s^{2} \sigma^{2}} .
\end{aligned}
$$

Here we use $\omega_{1}$ to denote the positive solution and $\omega_{2}$ to denote the negative solution. The bankruptcy threshold $V_{B}$ is derived by maximizing the value of equity with respect to $V_{B}$. Since $E(V)$ depends on 
$V_{B}$ only through $A_{3}$, the optimal level $V_{B}{ }^{*}$ is derived solving $\partial A_{3} / \partial V_{B}=0$. This value is given by the implicit expression: $\omega_{1} \beta\left(\frac{C}{r}\right) V_{B}^{-1}-\left(1+\omega_{1}\right) \rho \beta-\left(\omega_{1}-\omega_{2}\right) A_{2} V_{B}^{-\omega_{2}-1}=0$. Straightforward computation on (2) leads to the following:

Proposition 1. The value of the firm's equity decreases as the ambiguity perceived by the ambiguity averse DM increases.

An example ${ }^{7}$ is depicted in Figure 1 . The value of equity $E(V)$ is increasing in $V$, exhibiting the usual shape of a call-option. The default threshold $V_{B}$ is obtained as the intersection between the curve and the horizontal axis. Three different values of the parameter $c$ are used to show the effect of ambiguity on the equity value. The equity curve shifts downwards monotonically as $c$ decreases, that is, as ambiguity increases.

Figure 1 about here

The managerial implication of Proposition 1 is as follows. If DM has imprecise knowledge about the state of the world, and hence perceives the future as ambiguous, then he/she underestimates the upside potential because he/she makes decisions on "the worst case" scenario. This result contrasts with what is usually obtained for an increase in risk, as measured by the volatility $\sigma$. An increase in risk in the sense of mean-preserving spread raises the option value and hence lowers the default trigger. Indeed, the firm may capture the upside gains and minimize the downside loss, by staying in business longer in riskier situations, waiting for the risk to be partially resolved (see Dixit and Pindyck, 1994). Thus, the value of the firm's equity increases with volatility, while it decreases as ambiguity increases. The results in Remarks 1 and 2 follow as well:

\footnotetext{
${ }^{7}$ The parameter values are similar to Asvanunt, Broadie and Sundaresan (2011) and consistent with previous works (see Leland, 1994).
} 
Remark 1. The default threshold $V_{B}$ increases as the ambiguity perceived by the ambiguity averse DM increases.

As perceived ambiguity increases, equity holders choose a higher default level and hence enter financial distress earlier. This occurs because the value of the option to keep the firm open decreases with a higher ambiguity aversion bias, which reduces the variance in the Choquet-Brownian motion. Thus, ambiguity averse DMs default sooner because they undervalue the option value given by the continuation value of equity. This prediction seems to be consistent with the large amount of quick exits in recent recessions (Routledge and Zin, 2009), which contrasts with a risk prediction. Firms are more ambiguous about industry demand, productivity and when the economy will recover, making them less willing to hold the option and hence they exercise the option, i.e. default, earlier.

Remark 2. The value of the firm's equity decreases as the cost of equity dilution ( $\beta$ ) increases.

Therefore, with costly equity dilution, the effect of ambiguity on equity value is reinforced, because equity declines at a faster rate. As a consequence of Remark $2, V_{B}$ increases as $\beta$ increases.

Let us now determine the value of the firm's debt. If the firm liquidates its assets upon bankruptcy, a fraction $\alpha$ is lost due to liquidation costs. Thus, due to limited liability, debt holders will only receive $D\left(V_{B}\right)=(1-\alpha) V_{B}$. The value of the firm's debt $D(V)$ is determined in the Appendix and has the following expression:

$$
D(V)=\frac{C}{r}+\left((1-\alpha) V_{B}-\frac{C}{r}\right)\left(\frac{V}{V_{B}}\right)^{-\omega_{1}} \text { if } V \geq V_{B}
$$

The following Proposition holds:

Proposition 2. The value of the firm's debt increases as the ambiguity perceived by the ambiguity averse DM increases. 
An example is depicted in Figure 2, where the same parameters of Figure 1 are used. The debt value $\mathrm{D}(\mathrm{V})$ increases with $\mathrm{V}$, and for sufficiently large $\mathrm{V}$ it flattens out to the risk-free value $C / r$. Three different values of the parameter $c$ are used to show the effect of ambiguity on the debt value. The debt curve shifts upwards as $c$ decreases.

Figure 2 about here

Also this result contrasts with what is usually obtained for an increase in uncertainty as measured by the volatility $\sigma$ : the value of debt decreases with volatility, while it increases with ambiguity. Ambiguity averse DMs may over lever their firm because they scale down asset volatility. So the effects of risk and perceived ambiguity go in opposite directions.

The intuition of our results resembles that of a firm facing the corresponding ambiguous static decision problem. Following the requirement for dynamic consistency, assume the DM's beliefs can equivalently be represented by a probability distribution. An increase in the level of ambiguity changes the initial equivalent probability distribution into one whose mean and variance are reduced.

The firm is financed by equity and debt and is vulnerable to bankruptcy. The value of its equity is determined by limited liability considerations. An increase in ambiguity now tends to decrease the probability weight on high returns. As a consequence, the value of equity decreases. As in the results for the ambiguous stochastic process (Propositions 1 and 2), the effect of an increase in ambiguity is opposite to the standard effect of an increase in volatility.

In a nutshell: the limited liability effect of enhanced risk makes equity holders more aggressive, which increases default risk and reduces the value of debt. An increase in ambiguity, on the other hand, changes the stochastic process perceived by the DM by reducing both its mean and its variance, 
making equity holders less aggressive. This mitigates against the limited liability effect, by increasing the recovery rate in case of default.

\section{DISCUSSION AND IMPLICATIONS}

\subsection{PECKING ORDER FINANCING DECISIONS}

It is well-known that the general rule of the pecking order hypothesis for the issuance of securities suggests the order of preference to be: firstly internal funds, if available; then debt, if external funds are needed; and finally equity. This rule is discussed in the seminal contribution by Myers and Majluf (1984), and suggests that firms issue the securities that carry the smallest adverse selection cost, i.e. are least likely to be mispriced by imperfectly informed outside investors. Debt dominates new equity, because it is considered to be robust against mispricing.

However, debt can create information problems of its own if there is a significant probability of default. The pecking order hypothesis has been challenged within the theory of optimal design of securities under asymmetric information (see Giammarino and Neave (1982), Nachman and Noe (1994), and Fulghieri and Lukin, 2001). In addition, much empirical work challenges the pecking order hypothesis (see, e.g. Hennessy, Livdan and Miranda, 2010, Leary and Roberts, 2010, and Halov and Heider, 2011) $)^{8}$.

In this section we reconsider the pecking order puzzle within the framework of our model with ambiguity. Let us consider a situation where the DM's valuation reflects his/her ambiguity aversion bias, while the market's valuation is not biased by ambiguity aversion. Harvey and Siddique (2000) and Ang, Chen and Xing (2006) report that corporate boards often weigh differently the risks

\footnotetext{
${ }^{8}$ Leary and Roberts (2010), p. 332, write "For example, Shyam-Sunder and Myers (1999) conclude that the pecking order is a good descriptor of broad financing patterns; Frank and Goyal (2003) conclude the opposite. Lemmon and Zender (2004) conclude that a "modified" pecking order - which takes into account financial distress costs - it is a good descriptor of financing behaviour; Fama and French (2005) conclude the opposite. Frank and Goyal (2003) conclude that the pecking order better describes the behaviour of large firms, as opposed to small firms; Fama and French (2005) conclude the opposite. Finally, Bharath, Pasquariello and $\mathrm{Wu}$ (2009) argue that firms facing low information asymmetry account for the bulk of the pecking order's failings; Jung, Kim and Stulz (1996) conclude the opposite".
} 
correlated with downside losses vs those linked to upside gains, in a way which seems to be consistent with ambiguity aversion. On the other hand, despite ample evidence of ambiguity aversion in individual decision making, various studies find no or only limited ambiguity aversion surviving in financial markets, if ambiguity attitudes of market participants are very heterogeneous (see Fullbrunn, Rau and Weitzel (2014) and references therein; see also Olsson, 2014). So, we suppose that the DM believes that cash flows are described by expression (1) with $c<1 / 2$, whereas the market's valuation is as if the cash flows are described by expression (1) with $c=1 / 2$. By plotting $D(V) / E(V)$, we find for any value $V$ of the firm's assets, that when the ambiguity perceived by the ambiguity averse DM increases, $D(V) / E(V)$ increases as well (see Figure 3). This implies that the DM believes that equity is more overvalued by the market than debt. Hence, the DM will prefer issuing equity rather than debt, which results in a reversal of the standard pecking order financing behaviour.

Figure 3 about here

The argument can be summarized as follows:

Proposition 3. A reversal of the standard pecking order may occur if the ambiguity aversion bias of the DM exceeds that of market.

The result in Proposition 3 poses a challenge for the standard pecking order: managers may not (may) follow a pecking order if they have a larger (smaller) ambiguity aversion bias than the market's valuations. This result can be seen partly as a consequence of the fact that ambiguity aversion leads to a reduction of the drift of the stochastic process as perceived by the firm insider with respect to the external market. This means that ambiguity aversion effectively makes insiders more "pessimistic" than the external market. In this light, equity is preferred because insiders issue overvalued securities. 
The way this managerial bias affects the pecking order preferences may help explain the inconclusive cross-sectional findings on the observed heterogeneity in capital structures and standard pecking order predictions. Our result is also in keeping with the theoretical literature on the pecking order, showing that asymmetries relating to the information available to managers and to investors may lead to a reversal in the preferences (Giammarino and Neave, 1982, and Nachman and Noe, 1994, Hackbarth, 2008) $)^{9}$. These contributions, however, consider forms of asymmetric information, rather than differences in the ambiguity aversion bias.

Of course, if the market is more ambiguity averse than the manager, then the manager will prefer issuing debt rather than equity, and an increase in ambiguity aversion in the market will lead to aversion to equity, consistently with the pecking order prediction of financing decisions. Therefore, the theoretical predictions about the effects of ambiguity on capital structure are somewhat sensitive to the modeling framework and the divergence in ambiguity assessment.

\subsection{CORPORATE LIQUIDITY POLICIES}

Now suppose that the firm can hold cash reserves and assume that the accumulated net revenues up to time $t$ can be described by a Bachelier additive model. Its use simplifies the mathematical structure of our model and allows us to consider net cash flows that may become negative when the firm's revenues are insufficient to cover its costs. We assume the firm acts in the best interest of its equity holders and maximizes the expected present value of dividends up to default. We further assume that the firm has no access to capital markets and that equity dilution is not possible. As a consequence, default occurs as soon as the cash process net of the coupon payment, hits the threshold 0 . Denote the

\footnotetext{
${ }^{9}$ Nachman and Noe (1994) show that debt emerges as the solution of an optimal security design problem if and only if the private information held by firm insiders orders the distribution of firm value by conditional stochastic dominance. This condition is satisfied in Myers and Majluf (1984), but does not hold more generally.
} 
total dividends distributed up to time $t$ by $Z_{t}$, where $d Z_{t} \geq 0$. Now the firm's cash reserve $X_{t}$ evolves $\operatorname{according}^{10}$ to:

$$
\begin{aligned}
& d X_{t}=(r-q+m \sigma) d t+s \sigma d B_{t}-d Z_{t}, 0 \leq t \leq t_{0} \\
& d X_{t}=d Z_{t}=0, t \geq t_{0}
\end{aligned}
$$

with $X_{0}=x \geq 0$ being given. The firm chooses its liquidity policy to maximize its total profits, i.e the expected total discounted dividends

$$
\mathrm{E}_{x} \int_{0}^{\infty} e^{-r t} d Z_{t}
$$

Accordingly, we define $V(x)=\sup \mathrm{E}_{x} \int_{0}^{\infty} e^{-r t} d Z_{t}$ where the sup is taken over all admissible control policies. The problem reduces to the classical dividend policy problem, formulated as a mixed singular control/optimal stopping problem, as in Jeanblanc-Picquè and Shiraev (1995), Radner and Shepp (1996) and Decamps and Villeneuve (2007, 2013), but here the effects of ambiguity are incorporated into the model. Calculations following the same arguments as in this literature lead to the following solution:

Proposition 4. The value of the firm's assets is given by:

$$
\begin{array}{ll}
V(x)=\max \left(0, \frac{f(x)}{f^{\prime}\left(x^{*}\right)}\right), \text { for } & 0 \leq x \leq x^{*} \\
V(x)=x-x^{*}+V\left(x^{*}\right), \text { for } & x \geq x^{*}
\end{array}
$$

where

$$
\begin{aligned}
& f(x)=e^{A x}-e^{B x}, \\
& x^{*}=\frac{1}{A-B} \ln \left(\frac{B}{A}\right)^{2}
\end{aligned}
$$

\footnotetext{
${ }^{10}$ Expression (8) is obtained from $d X_{t}=(r-q) d t+\sigma d W_{t}-d Z_{t}$, where $W_{t}=m t+s B_{t}$ and $B_{t}$ is a Wiener process.
} 
and

$$
\begin{aligned}
& \frac{1}{A-B}=\frac{s^{2} \sigma^{2}}{2 \sqrt{(r-q+m \sigma)^{2}+2 r s^{2} \sigma^{2}}} \\
& \left(\frac{B}{A}\right)^{2}=\frac{\left(-(r-q+m \sigma)-\sqrt{(r-q+m \sigma)^{2}+2 r s^{2} \sigma^{2}}\right)^{2}}{\left(-(r-q+m \sigma)+\sqrt{(r-q+m \sigma)^{2}+2 r s^{2} \sigma^{2}}\right)^{2}} .
\end{aligned}
$$

The managerial implication of Proposition 4 is as follows. If the cash process falls below the coupon payment, this leads to immediate bankruptcy. Whenever the cash process exceeds the threshold value for paying out dividends, $x \geq x^{*}$, the optimal policy pays out all cash in excess of the threshold value $x^{*}$. If the cash process falls below the critical level $x^{*}$, but exceeds the coupon payment, then no dividends are paid, but bankruptcy is avoided.

This "all-or-nothing" policy is common to the classical dividend policy of the literature mentioned above. It finds that the optimal choice of $d Z_{t}$ is singular: in the "dividend" region where $x \geq x^{*}$, that is, where the liquidity reserve becomes too high, it is optimal to pay dividends as quickly as possible, reducing the cash holdings until either the liquidity reserve returns to the "save" region, where the firm will not pay dividends, or until the firm is bankrupt.

This formulation can be extended to allow the firm to issue new equity. In this case, another "issue" region will be added, lying below the "save" region, such that if the liquidity reserve becomes too low, then new equity is issued to return to the "save" region (see also Anderson and Carverhill, 2011). Another extension could consider lumpy investments and uncertain capital supply, which not only affects the pecking order of sources of finance, but also leads to several different regions relating to the firm's dividend policy (see Hugonnier, Malamud and Morellec, 2015). For the sake of simplicity, we do not pursue these possibilities here and instead focus on the effect of ambiguity within the classical framework.

To see how ambiguity affects the optimal dividend policy, we need to know how the critical threshold $x^{*}$ changes as $c$ changes. Calculation of $\partial x^{*} / \partial c$ leads to the following: 
Proposition 5. The critical threshold value of the cash process is non monotonic and increases (decreases) for high (low) levels of ambiguity aversion.

An example is provided in Figure 4, where the threshold $x^{*}+C$ is plotted against $c$, for $0<c<1 / 2$.

Figure 4 about here

The threshold can be seen as a liquidity target. As ambiguity increases up to a certain level, the threshold decreases. Dividends are "a bird in the hand", so ambiguity averse DMs prefer dividend payments, because they try to avoid uncertainties as much as possible (see Breuer, Rieger and Soypak, 2014b). As ambiguity increases, equity holders prefer to realize their gains as quick as possible. However, dividend payments increase the risk of default. Cash balances provide with cushions from premature liquidation. Thus, as DMs with a higher ambiguity aversion head toward bankruptcy, they will not empty out the cash balance, but retain cash, remaining solvent longer.

Notice that the effects of an increase in ambiguity aversion bias and an increase in volatility on the threshold do not align. Figure 5 depicts the critical threshold for $c=1 / 2$ as a function of volatility. We observe that the threshold is monotonically increasing in volatility.

Figure 5 about here

In summary, we find that cash holdings are retained longer if the DM's ambiguity aversion bias is sufficiently large. This result is consistent both with the observed change in cash holdings in periods of turbulence and vague uncertainty, and with the literature justifying large cash holdings because of the precautionary motive.

Bates, Kahle and Stulz (2009) showed that an increase in the cash-to-assets ratio of firms was related tightly to precautionary motives. They constructed a measure of cash-flow uncertainty and showed that firms with higher 
uncertainty in their cash flows had higher cash-to-assets ratios. Additionally, we find that for relatively small ambiguity aversion biases, cash holdings become less attractive. In this case, the DM prefers to receive dividends instead. This corporate dividend policy is consistent with the empirical findings of Breuer, Rieger and Soypak (2014b) that provide a cross-country analysis across a sample of 29 countries for which data on behavioral variables were collected via a comprehensive survey. They verified empirically that various measures of firms' dividend levels were increasing in ambiguity aversion.

\subsection{EMPIRICAL INSIGHTS}

Providing empirical support for our results is not straightforward, due to the difficulty in finding a convincing proxy for the size of the ambiguity aversion bias. Recent work by Rieger, Wang and Hens (2015) employs a methodology to measure the average ambiguity aversion across different countries, and this methodology might be adapted to our framework in order to estimate the level of the ambiguity aversion.

As a preliminary step we analyzed cross-country average leverage values - where leverage is defined as book value of long term debt (item 106 in Compustat Global database) over market value of total assets, calculated as book value of total assets (item 89) minus book value of equity (item 146) plus market value of equity (item MKVAL) - over a period of five years for 24 countries $^{11}$. The average ambiguity aversion across these countries is provided by Rieger, Wang and Hens (2015) and is mapped into the parameter $c$. We found a significant positive correlation (0.566) between leverage and ambiguity bias (see Figure 6), which is consistent with our results.

Figure 6 about here

Initial empirical evidence showing that ambiguity aversion is positively associated with cash holdings

\footnotetext{
${ }^{11}$ Australia, Austria, US, UK, Finland, Germany, Colombia, Sweden, Italy, New Zealand, France, The Netherlands, Switzerland, Argentina, Denmark, Malaysia, Portugal, Spain, Japan, Mexico, China, Chile, Canada, Thailand.
} 
is provided in Neamtiu, Shroff, White and Williams (2014). They show that when managers are faced with ambiguity about future investment payoffs, they are likely to reduce their capital expenditures and increase their cash holdings. They use the dispersion in forecasts of corporate profits from the Survey of Professional Forecasters as a proxy for the level of ambiguity.

In contrast, Breuer, Rieger and Soypak (2014a) find that for financially constrained firms cash holdings decrease with increasing ambiguity aversion, while they get inconclusive results for unconstrained firms. They employed the ambiguity aversion parameter obtained via the international test of ambiguity survey as in Rieger, Wang and Hens (2015). Although the above-mentioned results seem conflicting, they might benefit from being interpreted within the context of our model in Section 3.2, which offers a general framework for understanding corporate decisions under ambiguity.

\section{CONCLUSION}

In this study we examine the effects of ambiguity on corporate financial decisions and cash holdings. Following the capacity approach, we describe the firm value as a Choquet Brownian process, and predict that greater ambiguity will lead firms to decrease equity, increase debt and enter financial distress earlier. This study offers several contributions. First, we contribute to the ambiguity literature regarding the impact of ambiguity on corporate financial decisions, which has never been studied in a real-option framework like ours. Second, we contribute to the theoretical debate about the conditions under which a pecking order for the issuing of securities exists. Finally, we examine in which manner ambiguity affects corporate cash holdings. We show that cash holdings are retained longer if the investors' ambiguity aversion bias is sufficiently large, while cash holdings become less attractive when the combined impact of ambiguity and ambiguity aversion is relatively low. 
Overall, our results shed new light on some biases in corporate beliefs, which have implications for corporate finance. Our study shows that perceived ambiguity is a determinant in behavioural corporate finance and significantly affects managerial decisions. 


\section{REFERENCES}

Anderson, R. and A. Carverhill (2011), 'Corporate Liquidity and Capital Structure', Review of Financial Studies, Vol. 25, pp. $797-837$.

Ang, A., Chen, J. and Y. Xing (2006), 'Downside risk', Review of Financial Studies, Vol.19, 1191-1239.

Asano, T. and A. Shibata (2014), 'Natural capital investment under Knightian uncertainty', Environment and Development Economics, Vol. 19, 5, pp. 529-547

Asvanunt, A., M. Broadie and S. Sundaresan (2011), 'Managing Corporate Liquidity: Strategies and Pricing Implications', International Journal of Theoretical and Applied Finance, Vol. 14, pp. 369-406.

Bates, T., K. Kahle and R. Stulz (2009), 'Why Do U.S. Firms Hold So Much More Cash than They Used To?', Journal of Finance, Vol. 64, pp. 1985 - 2021.

Ben-David, I., Graham, J.R. and C.R. Harvey (2013), 'Managerial Miscalibration', The Quarterly Journal of Economics, Vol. 128, 4, pp. 1547-1584.

Boyarchenko, N. (2010),'Ambiguity Shifts and the 2007-2008 Financial Crisis', mimeo.

Breuer, W., M. Rieger and K. Soypak (2014a), 'Precautionary Cash Holdings and Ambiguity Aversion', Manuscript, Department of Finance, University of Aachen, Germany.

Breuer, W., M. Rieger and K. Soypak (2014b),'The Behavioural Foundations of Corporate Dividend Policy: a Cross-country Analysis', Journal of Banking and Finance, Vol. 42, 247-265.

Charness, G. and U. Gneezy (2010),'Portfolio Choice and Risk Attitudes: an Experiment', Economic Inquiry, Vol. 48, 1, pp. 133-146.

Chateauneuf, A., J. Eichberger and S. Grant (2007), 'Choice under Capacities with the Best and the Worst in Mind: Neo-Additive Capacities', Journal of Economic Theory, Vol. 137, pp. 538 - 567.

Chen Z. and L. Epstein (2002),'Recursive multiple-priors', Econometrica, Vol. 70,4, pp. 1403-1443

Decamps, J. and S. Villeneuve (2007), 'Optimal Dividend Policy and Growth Option', Finance and Stochastics, Vol. 11, pp. 3 - 27. 
Decamps, J. and S. Villeneuve (2013), 'Optimal Investment under Liquidity Constraints', in: Ambiguity, Real Options, Credit Risk and Insurance, ed. by A. Bensoussan, S. Peng and J. Sun, IOS Press, Amsterdam.

Denis, J. and V. Sibikov (2010), 'Financial Constraints, Investment and the Value of Cash Holding', Review of Financial Studies, Vol. 23, pp. 247 - 269.

Dixit, A. and R. Pindyck (1994), Investment under Uncertainty, Princeton University Press.

Driouchi, T., Trigeorgis, L. and Y. Gao (2015), Choquet-Based European Option Pricing with Stochastic (and Fixed) Strikes, Operations Research Spectrum, Vol. 37, pp.787-802

Driouchi, T., Trigeorgis, L. and R.H.Y. So (2015), Option implied ambiguity and its information content: evidence from the sub-prime crisis, Annals of Operations Research,pp.1-29

Ellsberg, D. (1961), 'Risk, Ambiguity and the Savage Axioms', Quarterly Journal of Economics, Vol. 75, pp. $643-669$.

Epstein L. and M. Schneider (2010), 'Ambiguity and asset markets', Annual Review of Financial Economics, Vol. 2, pp. 315-346.

Epstein L. and T. Wang (1994),'Intertemporal asset pricing under Knightian uncertainty, Econometrica, Vol.62, 2, pp. 283-322.

Faulkender, M. and R. Wang (2006), 'Corporate Financial Policies and the Value of Cash', Journal of Finance, Vol. 61, pp. 1957 - 1990.

Fulghieri, P. and D. Lukin (2001), 'Information Production, Dilution Costs and Optimal Security Design', Journal of Financial Economics, Vol. 61, pp. 3 - 42.

Fullbrunn, S., Rau, H.A. and U. Weitzel (2014)' Does ambiguity aversion survive in experimental asset markets?' Journal of Behaviour and Organization, Vol. 107, 810-826.

Gao, Y. and T. Driouchi (2013) "Incorporating Knightian uncertainty into real options analysis: using multiple priors in the case of rail transit investments", Transportation research Part B: Methodological, Vol. 55, pp.23-40

Giammarino, R. and E. Neave (1982), 'The Failure of Financial Contracts and the Relevance of Financial Policy', Working Paper No 82-3, Queen's University, Kingston Ontario, Canada. 
Gilboa, I., A. Postlewaite and D. Schmeidler (2008), 'Probability and Uncertainty in Economic Modelling', Journal of Economic Perspectives, Vol. 22, pp. 173 - 188.

Graham, J.R. and C.R. Harvey (2001) The theory and practice of corporate finance: evidence from the field, Journal of Financial Economics, 60, 187-243.

Hackbarth, D. (2008), 'Managerial Traits and Capital Structure Decisions', Journal of Financial and Quantitative Analysis, Vol. 43, pp. 843 - 882.

Hackbarth, D. (2009), 'Determinants of Corporate Borrowing: A Behavioral Perspective', Journal of Corporate Finance, Vol.15, 389-411.

Halov, N. and F. Heider (2011), 'Capital Structure, Risk and Asymmetric Information', Quarterly Journal of Finance, Vol. 1, pp. 767 - 781.

Harvey, C.R. and A. Siddique (2000),'Conditional Skewness in Asset Pricing Tests, Journal of Finance, Vol. 55, 1263-1295.

Hennessy, C., D. Livdan and B. Miranda (2010), 'Repeated Signalling and Firm Dynamics', Review of Financial Studies, Vol. 23, pp. 1981- 2023.

Holberg, G., G. Phillips and N. Prabhala (2014), 'Product Market Threats, Payouts, and Financial Flexibility', Journal of Finance, Vol. 69, pp. 293 - 324.

Hugonnier, J., S. Malamud and E. Morellec (2015), 'Capital Supply Uncertainty, Cash Holdings, and Investment', Review of Financial Studies, Vol. 28, pp.391-445.

Jeanblanc-Picquè, M. and A. Shiryaev (1995), 'Optimization of the Flow of Dividends', Russian Mathematics Surveys, Vol. 50, pp. 257 - 277.

Kast, R. and A. Lapied (2010), 'Dynamically Consistent Choquet Random Walk and Real Investments', Document de Recherche No 2010-21, LAMETA, Montpellier.

Kast, R., A. Lapied and D. Roubaud (2014), 'Modelling under ambiguity with dynamically consistent Choquet random walks and Choquet-Brownian motions', Economic Modelling, Vol. 38, pp. 495-503.

Kelsey, D. and W. Spanjers (2004), Ambiguity in partnerships, The Economic Journal, 114, 528-546 
Kahneman, D. and A. Tversky (1979) Prospect Theory: an Analysis of Decision under Risk, Econometrica, 47, 263-291

Knight, F. (1921), Risk, Uncertainty and Profit, Houghton Mifflin, Boston and New York.

Leary, M. and J. Roberts (2010), 'The Pecking Order, Debt Capacity, and Information Asymmetry', Journal of Financial Economics, Vol. 95, pp. 332-255.

Leland, H. (1994), 'Corporate Debt Value, Bond Covenants and Optimal Capital Structure', Journal of Finance, Vol. 49, pp. 1213 - 1252.

Lins, K., H. Servaes and P. Tufano (2010), 'What Drives Corporate Finance? An International Survey of Cash Holdings and Lines of Credit', Journal of Financial Economics, Vol. 98, pp. 160 - 176.

Miao J. and N. Wang (2011),'Risk, uncertainty and option exercise, Journal of Economic Dynamic and Control, Vol. 35, pp.442-461.

Mousavi, S. and G. Gigerenzer (2014), "Risk, uncertainty and heuristics", Journal of Business Research, pp.1671-1678.

Myers, S. and N. Majluf (1984), 'Corporate Financing and Investment Decisions when Firms have Information that Investors do not have', Journal of Financial Economics, Vol. 13, pp. 187 - 221.

Nachman, D. and T. Noe (1994), 'Optimal Design of Securities under Asymmetric Information', Review of Financial Studies, Vol. 7, pp. $1-44$.

Neamtiu, M., N. Shroff, H. White and C.D. Williams (2014), 'The Impact of Ambiguity on Managerial Investment and Cash Holdings', Journal of Business, Finance and Accounting, Vol. 41, pp. 1071-1099

Nishimura, K. and H. Ozaki (2007), 'Irreversible investment and Knightian uncertainty',Journal of Economic Theory, Vol. 136, 1, pp. 668-694.

Olsson, H (2014), "Measuring overconfidence: Methodological problems and statistical artifacts", Journal of Business Research, pp.1766-1770

Radner, R. and L. Shepp (1996), 'Risk vs Profit Potential: A Model of Corporate Strategy', Journal of Economic Dynamics and Control, Vol. 20, pp. 1373 - 1393.

Routledge, B. and S. Zin (2001), “Model Uncertainty and Liquidity”, NBER WP n. 8683. 
Rieger, M., M. Wang and T. Hens (2015), 'Risk Preferences around the World', Management Science, Vol. 61, pp. 637-648

Schmeidler, D. (1989), 'Subjective Probability and Expected Utility without Additivity', Econometrica, Vol. 57, pp. 571 - 587.

Shefrin H. (2009), Behavioralizing Finance, Foundations and Trends in Finance, vol 4, n. 1-2, 1-184

Shefrin H. and M. Statman, (1985) The Disposition to Sell Winners too Early and Ride Losers too Long: Theory and Evidence, The Journal of Finance, Vol. 40, 777-790

Thaler, R. (1980) 'Toward a Positive Theory of Consumer Choice', Journal of Economic Behaviour and Organization, Vol. 1, 39-60

Trautman S. T. and G. Van De Kuilen (2013),'Ambiguity attitudes' in Keren, G. and G. Wu (eds.) Blackwell Handbook of Judgment and Decision Making, Basil Blackwell, Oxford. 


\section{Appendix}

\section{Equity Value under Ambiguity}

Following the dynamic programming methods (see Dixit and Pindyck, 1994), we derive the value of equity by solving the system:

$$
\begin{aligned}
& \frac{1}{2} s^{2} \sigma^{2} V^{2} E^{\prime \prime}(V)+((r-q)+m \sigma) V E^{\prime}(V)-r E(V)+\beta(q V-C)=0 \quad \text { if } V_{B} \leq V<\frac{C}{q} \\
& \frac{1}{2} s^{2} \sigma^{2} V^{2} E^{\prime \prime}(V)+((r-q)+m \sigma) V E^{\prime}(V)-r E(V)+(q V-C)=0 \quad \text { if } V \geq \frac{C}{q}
\end{aligned}
$$

In addition, the following boundary conditions must be satisfied:

$B C: E\left(V_{B}\right)=0$

$$
\begin{aligned}
& V M: E\left(\frac{C}{q}\right)^{-}=E\left(\frac{C}{q}\right)^{+} \\
& S P: E^{\prime}\left(\frac{C}{q}\right)^{-}=E^{\prime}\left(\frac{C}{q}\right)^{+}
\end{aligned}
$$

that is, equity holders receive nothing at bankruptcy $(B C)$, and the value matching $(V M)$ and smooth pasting $(S P)$ conditions hold at $C / q$ (see also Asvanunt, Broadie and Sundaresan, 2011). Moreover, we impose the condition that $E(V)$ asymptotically behaves like $V$ when the firm's value approaches infinity.

We start by determining, the first and the second derivatives of the general solution to (A.1):

$$
\begin{aligned}
& E(V)=A_{0}+A_{1} V+A_{2} V^{-\omega_{2}}+A_{3} V^{-\omega_{1}}: \\
& E^{\prime}(V)=A_{1}-\omega_{2} A_{2} V^{-\omega_{2}-1}-\omega_{1} A_{3} V^{-\omega_{1}-1} \\
& E^{\prime \prime}(V)=\omega_{2}\left(\omega_{2}+1\right) A_{2} V^{-\omega_{2}-2}+\omega_{1}\left(\omega_{1}+1\right) A_{3} V^{-\omega_{1}-2}
\end{aligned}
$$

Substituting them into (A.1), we obtain: 


$$
\begin{aligned}
& \frac{1}{2} s^{2} \sigma^{2} V^{2}\left[\omega_{2}\left(\omega_{2}+1\right) A_{2} V^{-\omega_{2}-2}+\omega_{1}\left(\omega_{1}+1\right) A_{3} V^{-\omega_{1}-2}\right] \\
& +((r-q)+m \sigma) V\left[A_{1}-\omega_{2} A_{2} V^{-\omega_{2}-1}-\omega_{1} A_{3} V^{-\omega_{1}-1}\right] \\
& -r\left[A_{0}+A_{1} V^{-\omega_{2}}+A_{3} V^{-\omega_{1}}\right]+\beta(q V-C)=0
\end{aligned}
$$

Rearranging this expression by gathering the terms relating to $V, V^{-\omega_{1}}$ and $V^{-\omega_{2}}$ we find:

$$
\begin{aligned}
& V^{-\omega_{2}}\left[\frac{1}{2} s^{2} \sigma^{2} \omega_{2}\left(\omega_{2}+1\right) A_{2}-(r-q) \omega_{2} A_{2}-m \sigma \omega_{2} A_{2}-r A_{2}\right] \\
& +V^{-\omega_{1}}\left[\frac{1}{2} s^{2} \sigma^{2} \omega_{1}\left(\omega_{1}+1\right) A_{3}-(r-q) \omega_{1} A_{3}-m \sigma \omega_{1} A_{3}-r A_{3}\right] \\
& +\quad V\left(\beta q-q A_{1}+m \sigma A_{1}\right)-r A_{0}-\beta C=0
\end{aligned}
$$

Setting the coefficients equal to zero we obtain $A_{0}=-\beta \frac{C}{r}, A_{1}=\beta \frac{q}{q-m \sigma}$, and can determine $\omega_{1}$ and $\omega_{2}$ as specified in expression (2) in the main text, where $\omega_{1}$ is positive and $\omega_{2}$ negative.

Applying the same procedure to the general solution of (A.2), $E(V)=\hat{A}_{0}+\hat{A}_{1} V+\hat{A}_{2} V^{-\omega_{2}}+\hat{A}_{3} V^{-\omega_{1}}$, we find $\widehat{A_{0}}=-\frac{C}{r}$ and $\widehat{A_{1}}=\frac{q}{q-m \sigma}$. Since $\omega_{2}$ is negative, it follows that $\hat{A}_{2}=0$.

The remaining coefficients, $A_{2}, A_{3}$, and $\hat{A}_{3}$, as in expression (2), are now determined by solving the equations:

$B C: \quad \beta\left(\frac{q}{q-m \sigma} V_{B}-\frac{C}{r}\right)+A_{2} V_{B}^{-\omega_{2}}+A_{3} V_{B}^{-\omega_{1}}=0$

$V M: \quad \beta\left(\frac{C}{q-m \sigma}-\frac{C}{r}\right)+A_{2}\left(\frac{C}{q}\right)^{-\omega_{2}}+A_{3}\left(\frac{C}{q}\right)^{-\omega_{1}}=\frac{C}{q-m \sigma}-\frac{C}{r}+\hat{A}_{3}\left(\frac{C}{q}\right)^{-\omega_{1}}$

$S P: \quad \beta \frac{q}{q-m \sigma}-A_{2} \omega_{2}\left(\frac{C}{q}\right)^{-\omega_{2}-1}-A_{3} \omega_{1}\left(\frac{C}{q}\right)^{-\omega_{1}-1}=\frac{q}{q-m \sigma}-\hat{A}_{3} \omega_{1}\left(\frac{C}{q}\right)^{-\omega_{1}-1}$ 


\section{Debt Value under Ambiguity}

The value of the firm's debt $D(V)$ is determined solving the following equation:

$$
\frac{1}{2} s^{2} \sigma^{2} V^{2} D^{\prime \prime}(V)+((r-q)+m \sigma) V D^{\prime}(V)-r D(V)+C=0 \quad \text { for } V \geq V_{B}
$$

Considering $D(V)=B_{0}+B_{1} V+B_{2} V^{-\omega_{1}}$ as the general solution to (A.3), we obtain:

$$
\begin{aligned}
& \frac{1}{2} \sigma^{2} \omega_{1}^{2} B_{2} V^{-\omega_{1}}+\frac{1}{2} \sigma^{2} \omega_{1} B_{2} V^{-\omega_{1}}+(r-q) V B_{1}-(r-q) \omega_{1} B_{2} V^{-\omega_{1}}+m \sigma V B_{1}-m \sigma \omega_{1} B_{2} V^{-\omega_{1}} \\
& -r B_{0}-r B_{1} V-r B_{2} V^{-\omega_{1}}+C=0
\end{aligned}
$$

The coefficients $B_{0}$ and $B_{1}$ are determined by gathering the constant and the coefficient of the $V$ term and setting them equal to zero:

$$
\begin{aligned}
& -r B_{0}+C=0 \Rightarrow B_{0}=\frac{C}{r} \\
& (r-q) B_{1}+m \sigma B_{1}-r B_{1}=0 \Rightarrow B_{1}=0 .
\end{aligned}
$$

Finally, the coefficient $B_{2}$ is obtained from the boundary condition $D\left(V_{B}\right)=(1-\alpha) V_{B}$.

Indeed, $\frac{C}{r}+B_{2} V_{B}^{-\omega_{1}}=(1-\alpha) V_{B} \Rightarrow B_{2}=\left((1-\alpha) V_{B}-\frac{C}{r}\right) V_{B}^{\omega_{1}}$ 
Figure 1. Value of the firm's equity under ambiguity

$$
C=2.3, \sigma=0.2, r=0.05, q=0.03, \alpha=0.3, \beta=1
$$

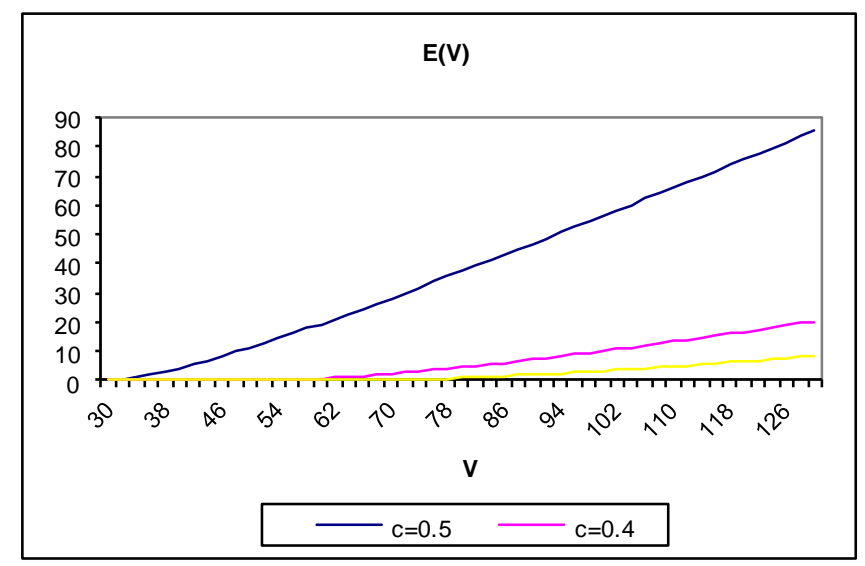

Figure 2 - Value of the firm's debt under ambiguity

$$
C=2.3, \sigma=0.2, r=0.05, q=0.03, \alpha=0.3, \beta=1
$$

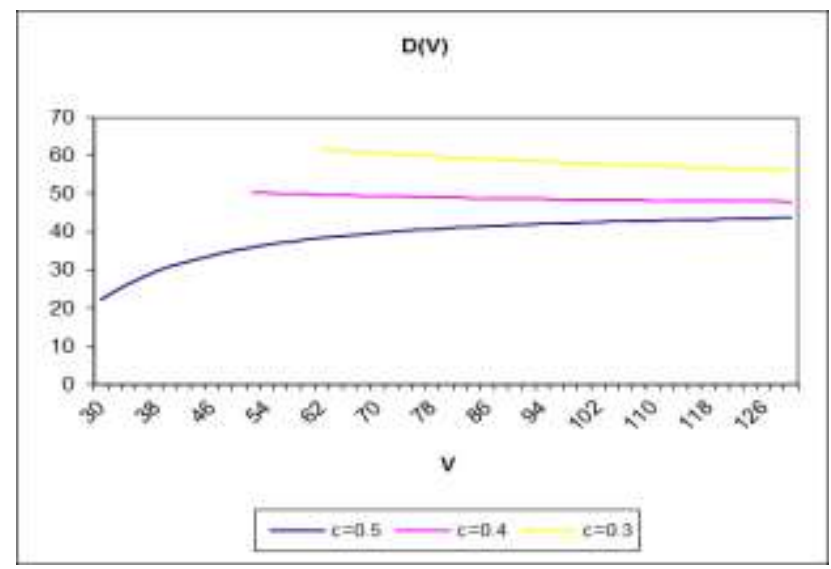


Figure 3 - Debt/Equity Value under ambiguity

$$
C=2.3, \sigma=0.2, r=0.05, q=0.03, \alpha=0.3, \beta=1
$$

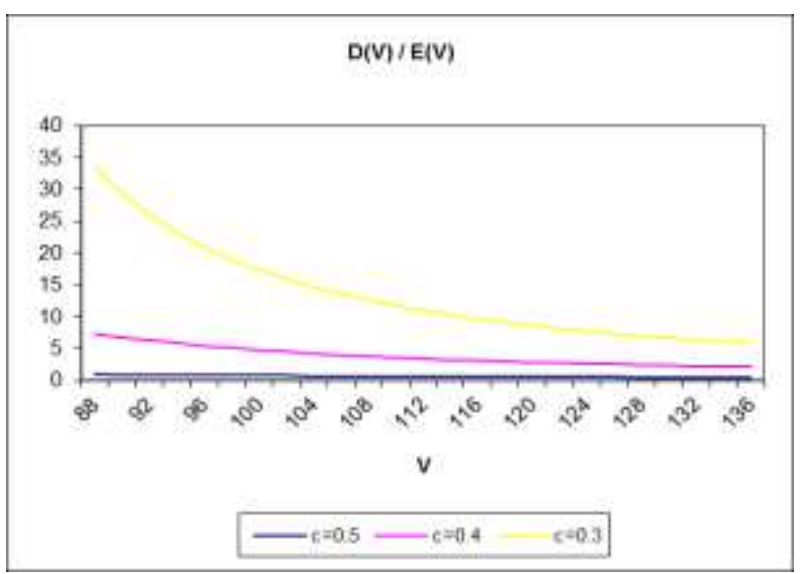

Figure 4-The threshold for different values of ambiguity

$$
C=2.3, \sigma=0.2, r=0.05, q=0.03
$$

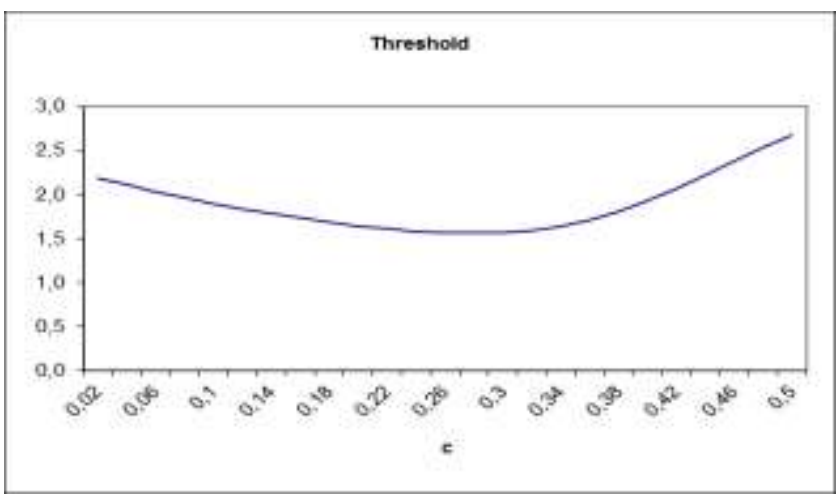


Figure 5 - The threshold for different values of volatility

$$
C=2.3, r=0.05, q=0.03, c=1 / 2 .
$$

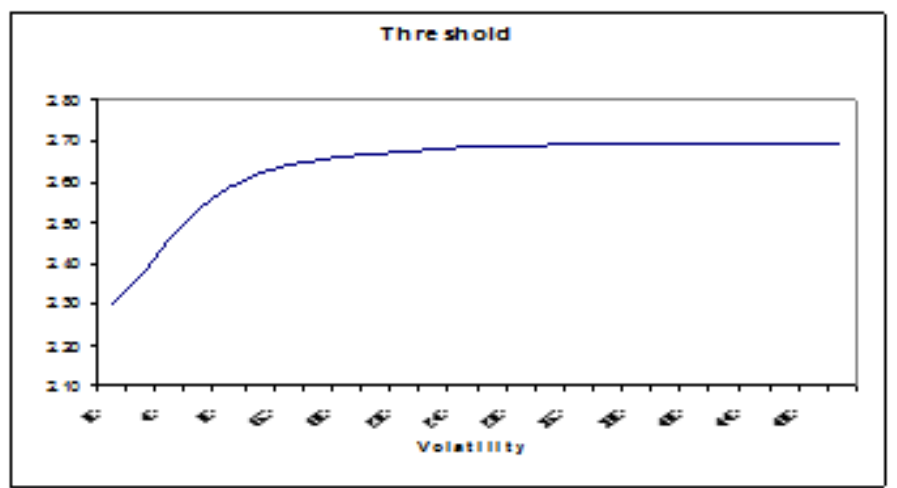

Figure 6. Cross-country leverage vs ambiguity aversion

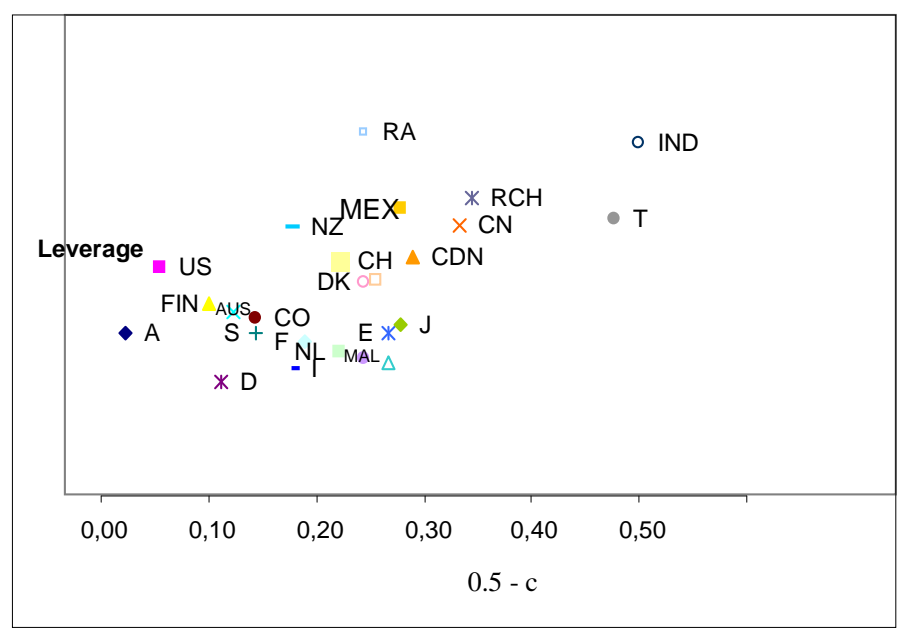

